\title{
Design Guidelines for In-Plane Mechanical Properties of SiC Fiber- Reinforced Melt-Infiltrated SiC Composites
}

\author{
Gregory N. Morscher, Ohio Aerospace Institute, Cleveland, $\mathrm{OH}$
}

Vijay V. Pujar, Materials and Simulation Technical Center, Goodrich Corporation, Brecksville, $\mathrm{OH}$

\begin{abstract}
In-plane tensile stress-strain, tensile creep, and after-creep retained tensile properties of melt-infiltrated SiC-SiC composites reinforced with different fiber types were evaluated with an emphasis on obtaining simple or first-order microstructural design guidelines for these in-plane mechanical properties. Using the mini-matrix approach to model stress-strain behavior and the results of this study, three basic general design criteria for stress and strain limits are formulated, namely a design stress limit, a design total strain limit, and an after-creep design retained strength limit. It is shown that these criteria can be useful for designing components for high temperature applications.
\end{abstract}

\section{INTRODUCTION}

Woven silicon carbide fiber-reinforced melt-infiltrated silicon carbide matrix composites are considered to be important enabling materials for high temperature turbine [1,2] applications. Melt-infiltrated (MI) matrix SiC composites are a subset of SiC/SiC ceramic matrix composites (CMC); however, even within that subset, considerable variation in thermomechanical properties are possible depending on the composite constituent materials, geometries, and content [3-6]. This is important for composite designers and fabricators who often have to weigh the benefits of cost savings, e.g., a less expensive fiber, with performance targets demanded by an application. Constituent-based and fiber-architecture-based design models need to be developed to assess whether a given fiber-type can meet property requirements or cost/performance objectives for a given application. To validate these models, composite property data are needed over wide variations in constituent compositions, geometries, and content. A considerable amount of data has been generated on composites with a wide variation in fiber fraction and fiber-architectures for the Sylramic-iBN fiber-reinforced MI composite system [4,7-11]. These results have enabled the development of simple constituent-based and fiber-architecture based relationships that can 
guide designers, fabricators, and end-users in predicting properties such as matrix cracking stresses, ultimate tensile properties, and elevated temperature creep and fatigue properties. Compared to other commercially available fibers, the Sylramic-iBN fiber evaluated in these studies is very stable against high temperature degradation both during processing and service, and as a result is expected to be less prone to mechanical performance variation arising from process and/or application variations [6]. However, the Sylramic-iBN fiber is not commercially available readily, and the other fiber-types may be more attractive as they offer an overall cost advantage over the Sylramic-iBN fiber in meeting the necessary property requirements for some applications.

The purpose of this study was to assess the in-plane mechanical performance of 2D 0/90 MI composites (oriented in one of the orthogonal fiber directions) reinforced with different commercially available polycrystalline SiC-based fibers. The fiber-types evaluated in this study included (1) the Tyranno ZMI fiber, (2) the Hi-Nicalon fiber, (3) the Tyranno SA-3 fiber, and (4) the Sylramic-iBN fiber. In this order, the fiber-types typically increase in modulus, creepresistance, high temperature capability, and acquisition cost. In addition, MI composite data reported previously [5] for the Hi-Nicalon Type-S fiber, another commercially available high modulus $\mathrm{SiC}$ fiber-type, are also included in this paper for comparison.

\section{EXPERIMENTAL}

Several fiber preforms consisting of four different fiber-types were produced by 0/90 symmetric lay-up of eight plies of 2D-woven 5-harness satin fabric with fiber content balanced in the two orthogonal directions. The preforms were then interphase coated with a thin layer of boron nitride by chemical vapor infiltration (CVI), followed by CVI SiC, slurry cast SiC, and silicon melt-infiltration (MI) producing what is commonly referred to as the slurry-cast meltinfiltration (SCMI) matrix composite [1,4,5]. Table 1 lists the panels evaluated in this study, and key constituent properties based on in-process panel data and measurements on different specimens from each panel. The panels included (1) three panels reinforced with Sylramic-iBN (NASA-treated Sylramic fiber produced by Dow Corning, Midland, MI [6]); (2) three panels with the Tyranno SA (Ube Industries, Japan); (3) one panel with Hi-Nicalon (Nippon Carbon, Tokyo, Japan); and (4) two panels with the Tyranno ZMI (Ube Industries, Japan). In addition, Table 1 also includes data from two panels with Hi-Nicalon Type-S (Nippon Carbon, Tokyo 
Japan) fiber that came from the earlier study [5], which is included in this paper for property comparison. For convenience, the composite panels are referred to as $\mathrm{xxx}-\mathrm{Y}$ where $\mathrm{xxx}$ is the reinforcing fiber type (Syl-iBN, SA, HN, ZMI, HNS) and Y is the panel number with that particular fiber.

For in-plane mechanical property evaluation, tensile specimens, 150 mm long and 12.6 $\mathrm{mm}$ wide at the ends, were machined from the panels into a dog-bone shape where the gage section length and width were approximately 25 and $10 \mathrm{~mm}$, respectively. The length of each specimen was aligned as close as possible with one of the two orthogonal fiber directions, commonly referred to as the $0^{\circ}$ direction. The ends of the tensile bars were encased in a wire mesh to alleviate grip stresses and bending moments at and near the pneumatic pressure grips. All tensile tests were performed along one of the two orthogonal fiber directions. Room temperature tensile tests were performed using a universal testing machine (Model 8562, Instron, Ltd., Canton, Mass.). Specimens were loaded at a constant rate of $4 \mathrm{kN} / \mathrm{min}$. Two clip-on strain gages (2.5\% max strain) were attached; one on each face, and the average of the two strain gages was used for determining the strain values for the tests. Unload-reload interruptions were also performed, usually at least two, in order to determine the residual stress in the composite matrix [12].

Modal acoustic emission (AE) was monitored during the room temperature tensile tests. A Fracture Wave Detector was used with wide-band pass frequency sensors (50 to 2,000 kHz), both from Digital Wave Corporation (Model B1025, Englewood, CO). Two AE sensors were placed on the face of the specimen, one on each side of the gage section, and approximately 50 to $60 \mathrm{~mm}$ from one another. The two AE sensors were synchronized, i.e., both sensors would record the waveform from the same event at the same time if either sensor was triggered. Events which occurred in the gage section (25 mm region of the extensometers) were sorted out using a threshold voltage crossing technique $[7,13]$ and used for analysis according to the location of each event based on the speed of sound of the extensional wave, which was determined post-test from events that occurred between the sensors [7,13]. Typically, 70\% of the AE activity events occurred outside the gage section and were not used in the AE analysis.

Elevated temperature tensile creep-rupture tests were performed at 1200 and $1315^{\circ} \mathrm{C}$ in ambient air on a different machine (Instron Model 5569), which had a resistance-heated $\mathrm{MoSi}_{2}$ element furnace inserted in the center of the dogbone section. The ends of the tensile bars in 
these tests were also encased in a wire mesh, but the pneumatic grips were water cooled. A contact extensometer with $\mathrm{SiC}$ contacting pins $25 \mathrm{~mm}$ apart from one another was used to measure strain at the edge of the specimen in the gage section. Displacement was measured with a LVDT that featured a maximum strain capability of $1 \%$. Prior to the elevated temperature creep test, a tensile modulus measurement was made on each specimen over the stress range 5 to 50 MPa at room temperature.

\section{RESULTS}

\section{Constituent Analyses}

Table 1 lists nominal and calculated values for key properties of the constituents in each composite panel, based on in-process data and data measured on the final processed panels and test specimens. Since the woven architectures for all panels were balanced in fiber content in the two orthogonal directions, the fiber volume fraction in the tensile loading direction, $\mathrm{f}_{\mathrm{o}}$, was half of the total fiber volume. For this study, $\mathrm{f}_{\mathrm{o}}$ was determined from the estimated total fiber area in the loading direction divided by the measured physical area of the composite specimen in the gage section; i.e.,

$$
\mathrm{f}_{\mathrm{o}}=\left(\mathrm{N}_{\mathrm{ply}} \mathrm{N}_{\mathrm{f}}\right)(\mathrm{epcm} / 10)\left(\pi \mathrm{R}_{\mathrm{f}}^{2}\right) / \mathrm{t}
$$

where $\mathrm{N}_{\text {ply }}$ is the known number of plies in the lay-up (eight for all the composites tested in this study); $\mathrm{N}_{\mathrm{f}}$ is the nominal number of fibers per tow; epcm/10 is the known tow ends per cm of the 2D weave (i.e., number of fiber tows per $\mathrm{cm}$ ) converted to $\mathrm{mm}$; $\mathrm{R}_{\mathrm{f}}$ is the nominal fiber radius in $\mathrm{mm}$; and $\mathrm{t}$ is the measured specimen thickness in $\mathrm{mm}$. Table 1 lists the calculated values for the total fiber volume, $\mathrm{f}=2 \mathrm{f}_{\mathrm{o}}$ for all specimens from each panel. Also listed in Table 1 are the nominal $\mathrm{N}_{\mathrm{f}}$ and $\mathrm{R}_{\mathrm{f}}$ values for each fiber type, as well as the specimen $\mathrm{t}$ values and specimen-tospecimen scatter in these $\mathrm{t}$ values.

\section{$\underline{\text { Room Temperature Stress Strain Behavior with Acoustic Emission }}$}

The average room temperature mechanical properties from the stress-strain tests are listed in Table II and some representative stress-strain curves are shown in Figure 1 for individual specimens from each composite system. In addition, the stress-strain behavior of a HNS-2 composite specimen from reference 5 is shown for comparison. In Figure 1, the hysteresis loops 
were removed for clarity; while Figure 2 shows representative stress-strain curves with the initial loops and the attendant residual stress for the different composite specimens. From these figures and Tables I and II, there are some general fiber-related observations that can be made concerning the as-fabricated composite specimens. First, as expected from composite theory [14], increasing the fiber volume fraction increased the composite secondary modulus as well as ultimate strength and strain. Second, for the higher modulus fibers ( $E_{\mathrm{f}} \sim 380 \mathrm{GPa}$ ), increasing the fiber volume fraction also increased the composite initial elastic modulus. This is consistent with the hypothesis that the effective modulus for the MI matrix in the loading direction is lower than that of the fiber. Third, composite specimens with the higher modulus fibers showed the matrix was under a mild compressive stress (Figure 2 and Table II); in contrast, specimens with approximately the same fraction of the lower modulus fiber showed the matrix essentially under zero to a very mild tensile residual stress. Fourth, for approximately the same fiber fraction, the lower modulus fibers exhibited higher composite ultimate strain, with the HNS panels being an exception.

Figure 3 shows the AE data from different specimens for each family of composites, collected during the tensile test. The AE parameter of interest is the energy of AE events which occur in the gage section. A single event was captured on two different sensors. The average energy from each event was determined and used to compute the cumulative energy of the events starting from the initial event until the final event. Figure 3 shows the normalized cumulative AE energy (NormCumAE), which is the cumulative energy divided by the total cumulative energy at the final event, plotted versus composite stress. It has been shown that for MI composites, NormCumAE is directly related to matrix crack density [7]. The decrease in the rate of NormCumAE at high stress is indicative of matrix crack saturation in the composite. In essence, the curves in Figure 3 show the relative distribution of matrix cracks as stress is increased in the different composite specimens, and complement the tensile stress-strain data in further understanding fiber effects on matrix cracking.

The AE Onset Stress has been shown to correspond to the onset of fiber-bridged matrix crack formation and is one measure of "matrix cracking stress" [7]. The AE Onset Stress is the onset of a high rate of high energy AE events and is determined by extrapolating the steep slope portion of the NormCumAE vs. stress curve back to the zero-axis [7]. Table II shows the average values for the AE Onset Stress. Also shown are the $0.005 \%$ offset stresses, from the stress-strain 
curves, a common technique for determining the proportional limit [15], and often associated with matrix cracking strengths for these composites. As shown in Figure 4, the AE Onset Stress and $0.005 \%$ Offset Stress are close in magnitude; however, the $0.005 \%$ Offset Stress almost always exceeded the AE Onset Stress for the composites of this study. The AE Onset Stress is considered to be a better parameter for matrix cracking since it is a direct measure of when matrix cracks actually occur.

There is a large scatter in stress over which AE activity occurs for the different composite systems (+/- $70 \mathrm{MPa}$ for the composites tested in this study - Figure 3). It has been shown in references 7 and 13 that the matrix cracking behavior of 2D woven MI composites with similar sized tows could be correlated with the stress in the region of the composite outside the loadbearing $0^{\circ}$ minicomposite, where the minicomposite consists of the $0^{\circ}$ fiber tow and its associated interphase coating and CVI SiC matrix. To estimate the in-situ stress on the “minimatrix" material, or the portion of the composite outside of the load-bearing $0^{\circ}$ minicomposite, including the $90^{\circ}$ minicomposites and the surrounding slurry-cast and meltinfiltrated material, it was shown in reference 7 that a simple rule of mixtures relationship could be used:

$$
\sigma_{\text {min imatrix }}=\frac{\left(\sigma_{c}+\sigma_{t h}\right)}{E_{c}}\left(\frac{E_{c}-f_{\min i} E_{\min i}}{1-f_{\min i}}\right)
$$

Here $\sigma_{\mathrm{c}}$ is the applied composite stress; $\sigma_{\mathrm{th}}$ is the residual stress within the as-fabricated composite; $E_{c}$ is elastic modulus of the composite; $E_{\text {mini }}$ is elastic modulus of the load-bearing $0^{\circ}$ minicomposite; and $\mathrm{f}_{\text {mini }}$ is the fraction of $0^{\circ}$ minicomposites in the composite. The composites of this study were all balanced weaves; therefore, $\mathrm{f}_{\text {mini }}$ is simply half the combined total fractions of fiber, BN and CVI SiC (Table I). $\mathrm{E}_{\text {mini }}$ was determined from the rule of mixtures of the fractions of the three components of the minicomposite where the fiber moduli used were $380 \mathrm{GPa}$ for Syl-iBN, SA, and HNS; 280 GPa for HN and 200 GPa for ZMI; the BN modulus was 25 GPa, and the CVI SiC modulus was $425 \mathrm{GPa}$. Plotting NormCumAE vs. $\sigma_{\text {minimatrix }}$, Figure 5 shows essentially that all of the AE behavior of the composites of this study now falls into a much narrower $\sigma_{\text {minimatrix }}$ range of less than $+/-20 \mathrm{MPa}$. This reduced range is similar to what was found for the MI composites processed by a different vendor in a previous study $[7,16]$.

For predictive modeling, an empirical two-parameter Weibull distribution for NormCumAE was best fitted to the data in Figure 4: 


$$
\text { NormCumAE }=1-\exp \left(\sigma_{\text {minimatrix }} / \sigma_{\text {minimatrix }}^{\mathrm{o}}\right)^{\mathrm{m}}
$$

where $\sigma^{\mathrm{o}}{ }_{\text {minimatrix }}$ is a reference stress and $\mathrm{m}$ is the Weibull modulus. For this study, the distribution function was only slightly different than that determined in reference 16 (see Figure 5). Also note that extrapolating the slope of the near linear region of the distribution represents a general $\sigma_{\text {minimatrix }}$ for onset of high energy AE activity, i.e., through-thickness matrix cracking. The stress corresponding to the onset of through-thickness matrix cracks is an important design parameter, since these cracks allow relatively easy access for oxidizing species into the composite and cause environmental degradation at elevated temperatures. This onset $\sigma_{\text {minimatrix }}, \sim$ $95 \mathrm{MPa}$, was about the same as that found in reference 16.

When multiplied by the final matrix crack density, Equation 4 can be used to derive a general relationship for matrix cracking in these $2 \mathrm{D}$ woven composites and can then be used to model stress/strain behavior for these composites [7]. For example, based on references 17 and 18, strain can be described as

$$
\varepsilon=\sigma / E_{c}+\alpha \delta \rho_{c} / E_{f}\left(\sigma+\sigma_{t h}\right) ; \quad \text { for } \rho_{c}{ }^{-1}>2 \delta
$$

where the stress-dependent crack density, $\rho_{c}$, can be found from Equation 3 multiplied by the final crack density and converted back into composite stress, the stress-dependent sliding length

$$
\delta=\alpha r\left(\sigma+\sigma_{\mathrm{th}}\right) / 2 \tau
$$

where $r$ is the fiber radius, $\tau$ is the interfacial shear stress, and

$$
\alpha=(1-f) E_{m} / f E_{c}
$$

$\mathrm{E}_{\mathrm{m}}$, the elastic modulus of the minimatrix, is assumed to be everything in the composite other than the load-bearing fibers and can be determined from rule of mixtures knowing $f_{0}, E_{f}$, and $E_{c}$. The only parameter not known is $\tau$ which can be determined by best fitting Eq. 5 to empirical stress strain behavior.

Figure 1b (circles) shows predicted stress-strain curves using the best fit $\tau$ values listed in Table III, which also shows the measured matrix crack densities. The maximum stress circle for the predicted stress-strain curves in Figure $1 \mathrm{~b}$ is the average fiber strength at failure (Table II) 
multiplied by the volume fraction of fibers in the loading direction (Table I). For the lower modulus fiber composites, slightly lower $\tau$-values were determined as would be expected for smoother surfaces and finer grain sizes of these fiber-types. However, for the composites reinforced with the polycrystalline fibers (Syl-iBN and SA), the $\tau$-values were unexpectedly low at $23 \pm 5 \mathrm{MPa}$. In an earlier study for MI composites fabricated with lower fiber volume fraction SA fibers, the best-fit $\tau$ was found to be between 40 and $50 \mathrm{MPa}$ [5]. For similar Syl-iBN composites from a different vendor [7], $\tau$ was found to be $\sim 70 \mathrm{MPa}$. This difference in $\tau$ is probably best explained by the thicker BN interphase thicknesses of this study $(\sim 1.0 \pm 0.1 \mu \mathrm{m})$ compared to the thinner BN interphases used $(\leq 0.5 \mu \mathrm{m})$ in the other studies $[4,5]$.

Using the minimatrix approach described above, it follows that a simple relationship for stress-strain behavior and matrix cracking can be established for a wide range of 2D 0/90 MI woven composite systems. The approach assumes that the matrix porosity is low enough so that matrix cracks emanate from the $90^{\circ}$ minicomposites in the $2 \mathrm{D}$ architecture and that this cracking mechanism is negligibly dependent on specimen width, length, and thickness (volume effects). It is shown here that this understanding can also be applied to creep-rupture properties, as discussed in the next section.

\section{Elevated Temperature Creep-Rupture Behavior}

Tensile creep-rupture studies were performed in ambient air at $1200^{\circ} \mathrm{C}$ for ZMI, SA, and Syl-iBN composites and at $1315^{\circ} \mathrm{C}$ for SA and Syl-iBN composites. Representative data on total strain vs. time data are shown in Figure 6 at 1200 and $1315^{\circ} \mathrm{C}$. The creep curves are dominated by a decreasing strain rate. A clear steady state or constant creep-rate region was never achieved in the creep tests employed for most specimens in this study. For specimens that failed in rupture during the test, a region of increasing strain rate just prior to rupture was typically observed. For specimens that survived the creep test, typically $~ 100$ hours, the test was stopped and either a fast-fracture test was performed at the creep temperature or the specimen was cooled down, removed from the rig and tested at room temperature, using similar unload-reload and AE monitoring as employed for the as-produced specimens. A limited number of specimens were tested for times greater than 100 hours to failure or up to 500 hours followed by retained tensile property measurements at room temperature. 
The rupture results are plotted as composite stress versus time at $1200^{\circ} \mathrm{C}$ and $1315^{\circ} \mathrm{C}$ in Figure 7. Note specimens that did not rupture are indicated by arrows. In general, the ruptureresistance directly correlates to the inherent creep and rupture resistance of the fibers, with Sylramic-iBN composites being the most, and ZMI composites being the least, creep and rupture resistant. Also note that there were considerable differences in fiber volume fraction between the different composite systems studied, which in effect further accentuated the differences in the creep performance in these composites. The Syl-iBN composites, or the composites with the most creep resistant fiber also had the highest fiber volume fractions and ZMI composites, or those with the least creep-resistant fiber had the lowest fiber volume.

Figure 7 also shows the predicted composite stress for the onset of matrix cracking at room temperature for some of the composite systems in their as-produced condition. This stress was calculated using Eq. 3 and $\sigma_{\text {minimatrix }}$ stress of $95 \mathrm{MPa}$, as described earlier in Figure 5. The differences in the composite onset stresses for the three different fiber composites are a result of differences in the elastic modulus values for the fiber types as well as constituent volume fractions, especially fiber volume differences between the composites. At $1200^{\circ} \mathrm{C}$, the rupture data (Figure 7a) show that the predicted onset cracking stress correlates very well with the runout conditions for all three composites systems. Since the onset of matrix cracks and resultant environmental attack through the cracks is the most common mechanism leading to composite rupture under tensile creep, this suggests that the room temperature criterion of $\sigma_{\text {minimatrix }}$ of 95 MPa for matrix crack onset holds for rupture up to $1200^{\circ} \mathrm{C}$ in these composites. At $1315^{\circ} \mathrm{C}$, the rupture data (Figure $7 \mathrm{~b}$ ) show that the predicted onset cracking stress intersects the rupture curves at $\sim 70$ hours for Syl-iBN composites and $\sim 10$ hours for the SA composites. In other words, composite rupture occurs well below the predicted onset stress derived from the $\sigma_{\text {minimatrix }}$ = $95 \mathrm{MPa}$ criterion. For the HNS composites from the earlier study, data from which are also included in Figure $7 \mathrm{~b}$, the $\sigma_{\text {minimatrix }}=95 \mathrm{MPa}$ criterion falls between a 20 hour rupture specimen and specimens that survived 100 hours. Other additional factors such as creep-controlled matrix crack growth come into play at these temperatures that contribute to rupture. Nevertheless, the composite cracking stress limit as predicted by Eq. 3 and the 95-MPa onset minimatrix stress offers a good first-order approach for designing against rupture in air at temperatures up to $1200^{\circ} \mathrm{C}$. 
Figure 8 shows the total strain in the composites plotted versus creep rupture time at $1200^{\circ} \mathrm{C}$ and $1315^{\circ} \mathrm{C}$ obtained from the same creep data at different stress levels. Of particular interest are specimens that ruptured at stresses below the predicted matrix onset stresses in the creep tests at $1315^{\circ} \mathrm{C}$. For both the Syl-iBN and SA specimens that were subjected to $1315^{\circ} \mathrm{C}$ creep (Figure 8b) at the lower stresses, the strain to failure for rupture was approximately $0.3 \%$. This may imply a creep strain limit for the initially uncracked or micro-cracked (no fiber-bridged cracks) matrix condition. Too little data is available for the HNS fiber at $1315^{\circ} \mathrm{C}$, and for all fiber-types in the tests at $1200{ }^{\circ} \mathrm{C}$. For the HNS composite tested at $1315^{\circ} \mathrm{C}$ (Figure 8b), the sole rupture specimen failed at $\sim 0.55 \%$ total strain and one $100 \mathrm{~h}$ interrupted specimen (138 MPa) survived $0.38 \%$ total strain. While the $\sim 0.3 \%$ strain limit is consistent with the data on both the SA and Syl-iBN fibers, it appears the ZMI composites in this study and the HNS composites in the earlier study can withstand higher strains at the lower stresses. Also, the HNS composites in the earlier study featured lower BN and CVI-SiC thickness, which may also have impacted these rupture results, and evidently additional data is needed to better understand the effect of fiber type and underlying mechanisms.

Based on the data from this study and the earlier HNS study, two basic design criteria can be formulated for long-time creep properties. The first is based on the stress above which significant matrix cracking occurs.. The composite stress that corresponds to $\sigma_{\text {minimatrix }}=95 \mathrm{MPa}$ gives a design stress limit. Staying below this stress in a CMC component is essential for longlife. The second is based on the total accumulated strain, i.e., elastic + time dependent creep strain. At applied stress levels below the design stress limit, rupture life is further limited by the total strain, which gives a design strain limit. Maintaining creep conditions in the component so that the total strain stays below this design total strain limit is also essential for long life. The value of this design total strain limit is dependent on the fiber-type in the composite. For both the Syl-iBN and SA composites, this total strain limit is about $0.3 \%$ total (elastic + time-dependent) strain. While additional testing and modeling efforts are required to understand the strain accumulation for variable stress-states and long times, the results from this study can be used to derive some simple models for creep. Much more effort is needed in this area to model the cause of transient creep and the effect of stress-time history, as well as understand the effect of constituent content variation on these properties. 


\section{$\underline{\text { Residual Properties after Creep }}$}

Specimens that did not rupture during the creep test were tested to determine their residual stress-strain behavior. Specimens were unloaded from the creep test at temperature and were either immediately reloaded to failure at the creep temperature or cooled (with no load) and tested at room temperature where AE was monitored during the test and two or three unloadreload loops were performed at increasing stress levels until composite failure. Some examples of the stress-strain behavior after creep are shown in Figure 9 along with room temperature and high temperature fast fracture curves. The tensile curves for the after-creep specimens are offset by the permanent deformation acquired during creep in the stress-strain plots in Figure 9. These plots therefore show the total accumulated mechanical strain prior to failure for the various asproduced and crept specimens. In all cases of this study, the total accumulated strain-to-failure is always less than the room-temperature strain-to-failure in the as-produced specimen. Little change was observed in elastic modulus for the retained strength tests whether tested at room temperature or at elevated temperature. It should be noted that the elastic modulus at temperature was on average $10 \%$ less than that measured at room temperature.

Figure 9 shows that one consequence of creep at stresses below which fiber-bridged matrix cracking occurs was that specimens exhibited a higher stress for non-linearity and through-thickness cracking after creep compared to as-produced composites, both at room temperature and at elevated temperature. This was observed for all three fiber-type composites in this study, and as reported previously [5] also for the HNS composites. The most dramatic increases were for the most creep-resistant fiber-type, Syl-iBN, composites. As reported previously [5], the cause of this increase is due to stress-relaxation in the matrix, particularly the Si-SiC particulate portion. This results in an increased compressive stress in the matrix upon unloading, which must be overcome to form bridged-matrix cracks $[19,20]$. As a further validation to this hypothesis, a Syl-iBN-3 composite specimen was pre-crept for 50 hours at $1315^{\circ} \mathrm{C}$ and $138 \mathrm{MPa}$. This was then crept at $1200^{\circ} \mathrm{C}$ at $220 \mathrm{MPa}$ (as noted in Figure $7 \mathrm{a}$ ). The pre-crept specimen ruptured after 58 hours of creep compared to only $0.3 \mathrm{~h}$ for the as-produced, no pre-creep, specimen, which represents an improvement of nearly two-orders of magnitude. With respect to stress, the pre-creep condition enabled this specimen to withstand a $25 \mathrm{MPa}$ higher stress than what would be expected for a virgin specimen, a 13\% improvement. This of course was only for one specimen; however, it is consistent with all the other observations on the 
after-creep properties and the proposed underlying mechanisms. This test also demonstrates that this concept offers the potential for boosting rupture life or rupture stress along the primary fiber directions for short time $(<100 \mathrm{~h})$ applications.

The residual ultimate tensile strength (UTS) of the crept composites is plotted versus total strain for specimens crept at 1200 and $1315^{\circ} \mathrm{C}$ in Figure 10 in a normalized form. This was done because composites varied in fiber volume fraction and composites of the same fiber-type may vary in as-produced strengths due to processing or fiber-lot variation (Table II). There is some scatter in the data and overlap between the retained strength values at the creep temperature compared to those at room temperature. However, there is relatively good agreement between the different composites. In general, under fast-fracture conditions, the $1200^{\circ} \mathrm{C}$ and $1315^{\circ} \mathrm{C}$ UTS values are $\sim 75 \%$ of the room temperature UTS for both the as-produced and crept composites (Figure 10a and b) and the 75\% value is steady up to a certain total accumulated strain. For the Syl-iBN and SA composites, this total strain is $\sim 0.2 \%$. For the HNS and ZMI composites, this appears to be higher. This is an encouraging result. The normalized after-creep retained strength is reduced with further increase in the total accumulated strains (Figure 10a and b). The HNS composites [5] show similar normalized retained strengths at $1315^{\circ} \mathrm{C}$ (Figure 10d), but maintained the relatively high retained strengths out to larger total strains, and did not show strength reduction in the range of strains explored in that study. Also note that two of the ZMI composites, which were tested at room temperature after creep, failed in the radius of the dogbone (marked with up-arrows in Figure 10a), or in the area of the specimen that was outside the hot zone region of the furnace, and $\sim 800 \pm 100^{\circ} \mathrm{C}$. Evidently these specimens suffered from intermediate temperature embrittlement [21,22].

The after-creep retained strength data offer a third general criterion for design, the aftercreep design retained strength limit, which is based on the creep-history dependent retained tensile properties. Under creep conditions that are well within both the design stress limit and the design strain limit, and up to a certain total strain value that is fiber-dependent, the retained tensile strengths can be assumed to be $\sim 75 \%$ of the room temperature as-produced ultimate strengths. For SA and Syl-iBN composites, this total strain value is $\sim 0.2 \%$, and for HNS it is higher than $0.3 \%$. At higher strains, but less than the design strain limit, a further knockdown would have to be factored in, depending on fiber type, for the retained strengths, as shown in 
Figures 10a and b. The after-creep design retained strength limit is useful for determining if the composite can survive a stress-transient after some thermal-stress loading. It should be noted that microscopic examination of polished longitudinal-sections of all of the specimens that survived $\geq$ $100 \mathrm{~h}$ creep did not possess fiber-bridged cracks with only one exception.

\section{DISCUSSION}

The general relationships for stress-strain behavior, creep-rupture and retained strength of 2D woven MI SiC/SiC composites developed from these results, provide the basis for a framework for composite materials selection, component design and life-modeling, as illustrated in Figure 11.

Stress-strain response: Based on a known or estimated local constituent content for a given or conceptual component architecture, the local stress-strain response due to initial thermal and mechanical loads and the onset stress for matrix cracking can be estimated from the minimatrix analysis. Both $\mathrm{E}_{\mathrm{c}}$ and $\sigma_{\mathrm{th}}$ at present need to be empirically determined, however, significant amount of empirical data for these properties already exist for a range of constituent contents. It is expected that models will also be developed for these properties in the near future for the entire range of constituent contents of interest.

Critical Stress for Matrix Cracking: Similar to that shown in Figure 7a, the effect of adjusting fiber or other constituent contents on the matrix cracking stress can be determined to assess the effect on stress-strain response and the onset matrix crack stress by assuming a value

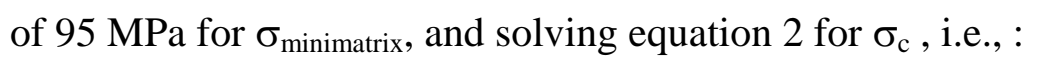

$$
\sigma_{c-\text { MatrixCracking }}=\frac{\left(95 \mathrm{MPa} \bullet E_{c}\right)}{E_{c}-f_{\min i} E_{\min i}}\left(1-f_{\min i}\right)-\sigma_{t h}
$$

For example, increasing $\mathrm{f}_{\text {mini, }}$, largely controlled by $\mathrm{f}_{\mathrm{o}}$, has the greatest effect on increasing matrix cracking stress. This stress would then pertain to the life-expectancy of the composite. Above

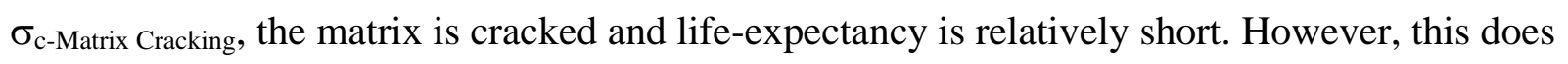
depend to some extent on fiber-type. For example, with Syl-iBN fibers life times exceeding 100

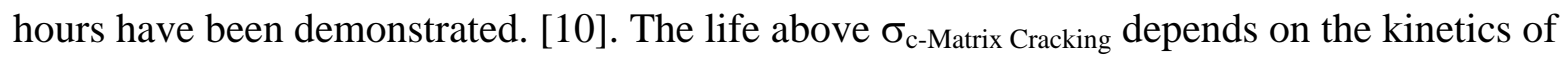


stressed-oxidation degradation and the rupture-strength of the fibers. The $1200^{\circ} \mathrm{C}$ data here show

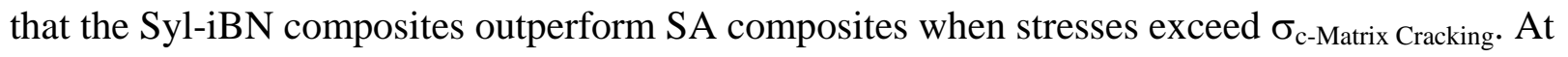
$1315^{\circ} \mathrm{C}$, the data would require a further "knockdown” in order to account for creep-controlled crack growth emanating from minicomposites tunnel cracks and ultimate failure.

Critical Strain to Failure For Creep: For the case where the applied stress is below $\sigma_{\mathrm{c}-M a t r i x}$ Cracking, the design total strain limit criterion of Figure $7 \mathrm{~b}$ can be applied for the case of creep at $1315^{\circ} \mathrm{C}$. This is $0.3 \%$ at $1315^{\circ} \mathrm{C}$ for both SA and Syl-iBN, and higher for HNS. It is also expected that this design total strain limit is temperature dependent. For example, a value of $\sim 0.4 \%$ was found for Syl-iBN MI composites at $1200^{\circ} \mathrm{C}$ [23]. If a tensile creep model exists which can account for the transient nature of creep in these systems, then the time it takes to reach the critical strain limit would indicate life-expectancy. If failure does not occur for the design life, then the retained properties can be determined from the relationships such as those inset in Figure 10c and $10 \mathrm{~d}$ for $1200^{\circ} \mathrm{C}$ and $1315^{\circ} \mathrm{C}$ creep conditions, respectively. In addition, if stress-transients occur during the application, relationships such as those in Figure 10a and 10b could be used to determine if the composite can withstand them which would then necessitate a new iteration with the new damage state and creep history.

\section{SUMMARY AND CONCLUSIONS}

In-plane room and elevated temperature mechanical properties of 2D woven meltinfiltrated composites reinforced with different commercial SiC fiber types were determined. As expected, the higher performance polycrystalline SiC fiber-types could survive to higher stresses and longer times at the higher temperatures. It was shown that the use of the minimatrix stress, i.e., the stress-parameter that correlates the matrix crack behavior via acoustic emission based on the assumption that matrix cracks are formed from $90^{\circ}$ minicomposites in a woven 2D composite, was an effective tool to model stress-strain behavior. The stress and strain dependence for creep was determined and related to the matrix cracking stress for $1200^{\circ} \mathrm{C}$ creep and to the total strain to failure for $1315^{\circ} \mathrm{C}$ creep rupture. From this work, several simple modeling and design relationships were determined for stress-strain behavior, onset of matrix cracking, long-term creep life stress, long-term creep strain limit, and residual mechanical properties after creep exposure. 
Based on the results of this study, three basic general design criteria are formulated for designing components for high temperature applications, namely a design stress limit, design strain limit and an after-creep design retained strength limit. The design stress limit corresponds to the matrix cracking strength derived from the mini-matrix approach. In the temperature regime where creep effects are minor $\left(\leq 1200^{\circ} \mathrm{C}\right)$, it is shown that it is essential that applied stresses remain below this design stress limit for long-term life. For higher temperatures $\left(1315^{\circ} \mathrm{C}\right)$ and higher creep-strain conditions at stresses below the design stress limit, long-term life of these composites is additionally limited by a design strain limit, which is the total accumulated strain including elastic strain and time-dependent creep strain. Maintaining creep conditions in the component so that the total strain stays below this design total strain limit is also essential for long life. It is further shown that this design strain limit is dependent on the fiber type with the Syl-iBN and SA fiber-types both having a design total strain limit of $~ 0.3 \%$ and the HNS fiber-type potentially having a higher value. The after-creep design retained strength limit is shown to be a function of the tensile strength of the as-produced specimen and the total strain experienced during creep, and can be useful for determining the maximum allowable stress-transient for a component given its prior in-service thermal load and creep history.

It is hoped that the results of this work will be helpful to designers and materials selectors when considering the property vs. cost trade-offs for CMC's in general and when comparing CMCs to other competing materials. In addition, the data presented here will be useful for the development and validation of more complex mechanical behavior models. This is especially important for understanding some of the nuances introduced with different fiber types and different constituent contents.

\section{ACKNOWLEDGEMENTS:}

This work was funded by both internal Goodrich and NASA Supersonic programs as well as a partially reimbursable Space Act Agreement between Goodrich and NASA.

\section{REFERENCES:}

1. D. Brewer, "HSR/EPM Combustor Materials Development Program”. Mater. Sci. Eng. A, A261, 284-291 (1999). 
2. C.M. Grondahl, and T. Tsuchiya, "Performance benefit assessment of ceramic components in a MS9001FA gas turbine”, Proceedings of ASME Turbo Expo 1998: Power for Land, Sea, and Air, ASME. 98-GT-186 (1998).

3. G.N. Morscher and J.Z. Gyekenesi, "Room Temperature Tensile Behavior and Damage Accumulation of Hi-Nicalon Reinforced SiC Matrix Composites," Ceram. Eng. Sci. Proc., 19[3]241-249 (1998)

4. G.N. Morscher and V.V. Pujar, "Melt-Infiltrated SiC Composites for Gas Turbine Engine Applications," Proceedings of ASME Turbo Expo 2004: Power for Land, Sea, and Air, June 14-17, 2004, Vienna, Austria paper no. GT2004-54233

5. G.N. Morscher and V. V. Pujar, "Creep and Stress-Strain Behavior After Creep for SiC Fiber Reinforced, Melt-Infiltrated SiC Matrix Composites” J. Am. Ceram. Soc. 89 [5] 1652-1658 (2006)

6. J.A. DiCarlo, H-M. Yun, G.N. Morscher, and R.T. Bhatt, "SiC/SiC Composites for $1200^{\circ} \mathrm{C}$ and Above" Handbook of Ceramics Composites, Chapter 4; pp. 77-98 (Kluwer Academic; NY, NY: 2005)

7. G.N. Morscher, "Stress-Dependent Matrix Cracking in 2D Woven SiC-fiber Reinforced Melt-Infiltrated SiC Matrix Composites”, Comp. Sci. Tech., 64 pp. 1311-1319 (2004)

8. G.N. Morscher, H.M. Yun, J.A. DiCarlo, "Matrix Cracking in 3D Orthogonal MeltInfiltrated SiC/SiC Composites with Various Z-Fiber Types", J. Am. Ceram. Soc., 88 [1] 146-153 (2005)

9. G.N. Morscher, H.M. Yun, and J.A. DiCarlo, "In-Plane Cracking Behavior and Ultimate Strength for 2D Woven and Braided Melt-Infiltrated SiC/SiC Composites Tensile Loaded in Off-Axis Fiber Directions," J. Am. Ceram. Soc., in print

10. G.N. Morscher, G. Ojard, R. Miller, Y. Gowayed, U. Santhosh, J. Ahmed, and R. John, "Tensile Creep and Fatigue of Sylramic-iBN Melt-Infiltrated SiC Matrix Composites: Retained Properties, Damage Development, and Failure Mechanisms” Comp. Sci. Tech.. submitted

11. V.V. Pujar and G.N. Morscher, "Tensile Creep Behavior of Melt-Infiltrated SiC-SiC Composites for Gas Turbine Engine Applications,” Proceedings of ASME Turbo Expo 2007: Power for Land, Sea, and Air, May 14-17, 2007, Montreal, Canada paper no. GT2007-27491

12. M. Steen and J.L. Valles, ASTM STP 1309, M.G. Jenkins et al., Eds. American Society for Testing and Materials, West Conshohocken, PA, 1997, pp. 49-65

13. G.N. Morscher, "Modal Acoustic Emission of Damage Accumulation in a Woven SiC/SiC Composite,” Comp. Sci. Tech. 59 687-697 (1999).

14. J. Aveston, G.A. Cooper, and A. Kelly, "Single and Multiple Fracture," Proceedings of the Properties of Fibre Composites Conference, IPC Science and Tech. Press, Ltd., Guildford, Surrey, England, pp. 15-24 (1971)

15. S. Kalluri, A. Calomino, and D. N. Brewer, "An Assessment of Variability in the Average Tensile Properties of a Melt-Infiltrated SiC/SiC Composite,'” Ceram.Eng. Sci. Proc., 25 [4] 79-86 (2004).

16. G.N. Morscher, "Matrix Cracking in Four Different 2D SiC/SiC Composite Systems", Published in the $35^{\text {th }}$ International SAMPE Technical Conference Proceedings (CD), Dayton, OH (2003)

17. W.A. Curtin, B.K. Ahn, and N. Takeda, Acta mater., Vol. 46, No. 10, (1998) pp. 34093420. 
18. A.W. Pryce and P.A. Smith, Br. Ceram. Trans., Vol. 92, No. 2 (1993) 49-54.

19. J.W. Holmes, "Influence of Stress Ratio on the Elevated-Temperature Fatigue of a Silicon Carbide Fiber-Reinforced Silicon Nitride Composite,” J. Am. Ceram. Soc., 74 [7] 1639-45 (1991)

20. S. Widaja, K. Jakus, J.E. Ritter, E. Lara-Curzio, T.R. Watkins, E.Y. Sun, and J.J. Brennan, "Creep-Induced Residual Strengthening in a Nicalon-Fiber-Reinforced BMASGlass-Ceramic-Matrix Composite,” J. Am. Ceram. Soc., 82 [3] 657-721 (1999)

21. F.E. Heredia, J.C. McNulty, F.W. Zok, and A.G. Evans, "Oxidation embrittlement probe for ceramic-matrix composites” J. Am. Ceram. Soc., 78, 2097 (1995).

22. G.N. Morscher and J.D. Cawley, "Intermediate Temperature Strength Degradation in SiC/SiC Composites,” J. European Ceramic Society, vol. 22, no. 14-15, pp. 2777-2788 (2002)

23. G. Ojard, A. Calomino, G. Morscher, Y. Gowayed, U. Santhosh, J. Ahmad, R. Miller, and R. John, "Post Creep/Dwell Fatigue Testing of MI SiC/SiC Composites,” Ceram. Eng. Sci. Proc, (2007) in print 
Table I: Composite Physical Properties

\begin{tabular}{|c|c|c|c|c|c|c|c|c|}
\hline Panel & $\begin{array}{l}\text { Fiber- } \\
\text { type }\end{array}$ & $\begin{array}{c}\text { Avg } \\
\text { fiber } \\
\text { radius, } \\
\mu \mathrm{m}\end{array}$ & $\begin{array}{l}\text { \# of } \\
\text { fibers } \\
\text { per } \\
\text { tow }\end{array}$ & epcm & $\begin{array}{l}\text { Avg specimen } \\
\text { thickness, mm }\end{array}$ & $\begin{array}{c}\text { Average f } \\
\text { [\# specimens] } \\
\text { (scatter) }\end{array}$ & $\begin{array}{c}\text { Average } \\
\mathbf{f}_{\mathrm{BN}}^{*}\end{array}$ & $\begin{array}{l}\text { Average } \\
\text { f }_{\text {CVI SiC }}\end{array}$ \\
\hline SYLiBN-1 & $\begin{array}{l}\text { Sylramic- } \\
\text { iBN }\end{array}$ & 5 & 800 & 7.9 & $\begin{array}{c}2.26[11] \\
(+0.07 /-0.19) \\
\end{array}$ & $\begin{array}{c}0.352[11] \\
(+0.014 /-0.004)\end{array}$ & 0.114 & 0.286 \\
\hline SYLiBN-2 & $\begin{array}{l}\text { Sylramic- } \\
\text { iBN }\end{array}$ & 5 & 800 & 7.9 & $\begin{array}{c}2.05[10] \\
(+0.14 /-0.12)\end{array}$ & $\begin{array}{c}0.386[10] \\
(+0.026 /-0.022)\end{array}$ & 0.157 & 0.287 \\
\hline SYLiBN-3 & $\begin{array}{c}\text { Sylramic- } \\
\text { iBN }\end{array}$ & 5 & 800 & 7.9 & $\begin{array}{c}1.93[10] \\
+0.09 \\
\end{array}$ & $\begin{array}{c}0.410[10] \\
(+0.02 /-0.018)\end{array}$ & 0.134 & 0.270 \\
\hline SA-1 & $\begin{array}{c}\text { Tyranno } \\
\text { SA3 }\end{array}$ & 5 & 800 & 7.1 & $\begin{array}{c}2.05[7] \\
(+0.06 /-0.12) \\
\end{array}$ & $\begin{array}{c}0.348[7] \\
(+0.02 /-0.01)\end{array}$ & 0.120 & 0.281 \\
\hline SA-2 & $\begin{array}{l}\text { Tyranno } \\
\text { SA3 }\end{array}$ & 5 & 800 & 7.1 & $\begin{array}{c}1.97[5] \\
(+0.04 /-0.05)\end{array}$ & $\begin{array}{l}0.362[5] \\
( \pm 0.008)\end{array}$ & 0.126 & 0.281 \\
\hline SA-3 & $\begin{array}{c}\text { Tyranno } \\
\text { SA3 } \\
\end{array}$ & 5 & 800 & 7.1 & $\begin{array}{c}2.15[10] \\
(+0.05 /-0.08) \\
\end{array}$ & $\begin{array}{c}0.332[10] \\
(+0.006 /-0.004) \\
\end{array}$ & 0.098 & 0.274 \\
\hline $\mathrm{HN}$ & $\begin{array}{c}\text { Hi- } \\
\text { Nicalon }\end{array}$ & 6.85 & 500 & 7.1 & $\begin{array}{c}3.05[7] \\
(+0.11 /-0.13)\end{array}$ & $\begin{array}{c}0.274[7] \\
(+0.012 /-0.01)\end{array}$ & 0.039 & 0.227 \\
\hline Z-1 & $\begin{array}{c}\text { Tyranno } \\
\text { ZMI }\end{array}$ & 5.5 & 800 & 8.7 & $\begin{array}{c}3.75[9] \\
+0.06\end{array}$ & $\begin{array}{c}0.281[9] \\
(+0.004 /-0.006)\end{array}$ & 0.082 & 0.227 \\
\hline Z-2 & $\begin{array}{c}\text { Tyranno } \\
\text { ZMI }\end{array}$ & 5.5 & 800 & 8.7 & $\begin{array}{c}3.62[4] \\
(+0.12 /-0.14)\end{array}$ & $\begin{array}{c}0.292[4] \\
(+0.01 /-0.01)\end{array}$ & 0.072 & 0.198 \\
\hline HNS-1 $^{[6]}$ & $\begin{array}{c}\text { Hi- } \\
\text { Nicalon S }\end{array}$ & 6.5 & 500 & 7.1 & $\begin{array}{c}2.49[7] \\
(+0.04 /-0.09)\end{array}$ & $\begin{array}{c}0.302[9] \\
(+0.012 /-0.004)\end{array}$ & 0.04 & 0.25 \\
\hline HNS-2 ${ }^{[6]}$ & $\begin{array}{c}\text { Hi- } \\
\text { Nicalon S }\end{array}$ & 6.5 & 500 & 7.1 & $\begin{array}{c}2.17[9] \\
(+0.08 /-0.12)\end{array}$ & $\begin{array}{c}0.348[9] \\
(+0.020 /-0.018)\end{array}$ & 0.04 & 0.21 \\
\hline
\end{tabular}

* The preforms were de-tooled after CVI SiC infiltration. Therefore, the volume of BN could not be measured directly from weight gain. Instead, the volume of BN was estimated from average BN thickness measurements of polished specimens. The volume of SiC was determined from the weight gain after CVI infiltration after subtracting the estimated weight of BN and the known weights of the fibers for the panel preform. The fiber, BN, and CVI SiC densities used were 3.05, 1.5, and $3.2 \mathrm{~g} / \mathrm{cc}$, respectively. 
Table II: Composite Room Temperature Mechanical Properties

\begin{tabular}{|c|c|c|c|c|c|c|c|}
\hline Panel & $\begin{array}{c}\text { Avg. E, GPa } \\
\text { [\#RT spec] } \\
\text { (scatter) }\end{array}$ & $\begin{array}{l}\text { Avg. UTS, } \\
\text { MPa } \\
\text { [\# specimens] } \\
\text { (scatter) }\end{array}$ & $\begin{array}{c}\text { Avg. } \varepsilon, \% \\
\text { [\# specimens] } \\
\text { (scatter) }\end{array}$ & $\begin{array}{l}\text { Avg. Stress on } \\
\text { Fibers, GPa } \\
\text { [\#RT spec] } \\
\text { (scatter) }\end{array}$ & $\begin{array}{c}0.005 \% \\
\text { Offset } \\
\text { Stress, } \\
\text { MPa }\end{array}$ & $\begin{array}{c}\text { AE } \\
\text { Onset } \\
\text { Stress, } \\
\text { MPa }\end{array}$ & $\begin{array}{c}\text { Residual } \\
\text { stress, } \\
\text { MPa }\end{array}$ \\
\hline SYLiBN-1 & $\begin{array}{c}247[3] \\
(+0.007 /- \\
0.006)\end{array}$ & $\begin{array}{c}361[3] \\
(+36 /-32)\end{array}$ & $\begin{array}{c}0.35[3] \\
(+0.04 /-0.06)\end{array}$ & $\begin{array}{c}1997[2] \\
(+79 /-143)\end{array}$ & $\begin{array}{c}194[3] \\
(+6 /-9)\end{array}$ & $\begin{array}{c}192[2] \\
\pm 2\end{array}$ & $\begin{array}{c}-60[3] \\
\pm 7\end{array}$ \\
\hline SYLiBN-2 & $\begin{array}{c}271[2] \\
( \pm 12)\end{array}$ & $\begin{array}{c}465[2] \\
+37 \\
\end{array}$ & $\begin{array}{l}0.47[2] \\
\pm 0.03\end{array}$ & $\begin{array}{c}2368[2] \\
+75\end{array}$ & $\begin{array}{l}181[2] \\
\pm 4\end{array}$ & $\begin{array}{c}189[2] \\
+16 \\
\end{array}$ & $\begin{array}{c}-60[2] \\
+10\end{array}$ \\
\hline SYLiBN-3 & 238 [1] & 444 [1] & $0.45[1]$ & 2210 [1] & 176 [1] & 155 [1] & $-45[1]$ \\
\hline SA-1 & 254 [1] & 358 [1] & 0.33 [1] & 2000 [1] & 152 [1] & 145 [1] & $-20[1]$ \\
\hline SA-2 & 236 [1] & 372 [1] & 0.34 [1] & 2047 [1] & 178 [1] & 138 [1] & -15 [1] \\
\hline SA-3 & 230 [1] & 334 [1] & 0.30 [1] & 1978 [1] & 178 [1] & 135 [1] & $-30[1]$ \\
\hline $\mathrm{HN}$ & $\begin{array}{c}244[7] \\
(+43 /-31)\end{array}$ & $\begin{array}{c}311[7] \\
(+17 /-10)\end{array}$ & $\begin{array}{c}0.79[7] \\
(+0.12 /-0.04)\end{array}$ & $\begin{array}{c}2272[7] \\
(+208 /-141)\end{array}$ & $\begin{array}{l}126[6] \\
(+4 /-5)\end{array}$ & $\begin{array}{c}114[6] \\
(+12 /-8)\end{array}$ & $\begin{array}{c}-4[6] \\
(+7 /-8)\end{array}$ \\
\hline $\mathrm{Z}-1$ & $\begin{array}{l}213[4] \\
(+5 /-3)\end{array}$ & $\begin{array}{c}279[3] \\
(+9 /-6) \\
\end{array}$ & $\begin{array}{c}0.95[3] \\
(+0.04 /-0.03) \\
\end{array}$ & $\begin{array}{c}1973[4] \\
(+66 /-35)\end{array}$ & $\begin{array}{l}111[4] \\
(+7 /-6)\end{array}$ & $\begin{array}{c}85[4] \\
(+10 /-15)\end{array}$ & $\begin{array}{l}+12[4] \\
(+5 /-9)\end{array}$ \\
\hline Z-2 & $\begin{array}{c}202[4] \\
(+5 /-3)\end{array}$ & $\begin{array}{c}261[4] \\
(+12 /-6)\end{array}$ & $\begin{array}{c}0.83[4] \\
(+0.02 /-.0 .03)\end{array}$ & $\begin{array}{c}1794[4] \\
(+49 /-53)\end{array}$ & $\begin{array}{r}107[4] \\
(+5 /-4)\end{array}$ & $\begin{array}{c}83[4] \\
(+11 /-14)\end{array}$ & $\begin{array}{l}+12[4] \\
(+8 /-7)\end{array}$ \\
\hline HNS-1 ${ }^{[6]}$ & 262 [1] & 341 [1] & 0.63 [1] & 2278 [1] & 154 [1] & 150 & -20 \\
\hline HNS-2 $^{[6]}$ & 232 [1] & 412 [1] & 0.60 [1] & $2245[1]$ & 147 [1] & 135 & -20 \\
\hline
\end{tabular}


Table III: Matrix Crack Density and Interfacial Shear Stress

\begin{tabular}{|c|c|c|}
\hline Panel & $\begin{array}{c}\text { Final measured } \\
\text { crack density } \\
\# / \mathbf{m m}\end{array}$ & $\begin{array}{c}\text { Best fit } \boldsymbol{\tau} \\
\mathbf{M P a}\end{array}$ \\
\hline SYLiBN-1 & 7.5 & 25 \\
\hline SYLiBN-2 & 8.1 & 18 \\
\hline SYLiBN-3 & 7.9 & 20 \\
\hline & & 28 \\
\hline SA-1 & 7.8 & \\
\hline & & \\
\hline HN & 2 & 20 \\
\hline & & \\
\hline Z-1 & 4.1 & 36 \\
\hline & & 20 \\
\hline HNS-1 ${ }^{[6]}$ & 7.0 & \\
\hline HNS-2 & & \\
\hline & 6.4 & \\
\hline
\end{tabular}




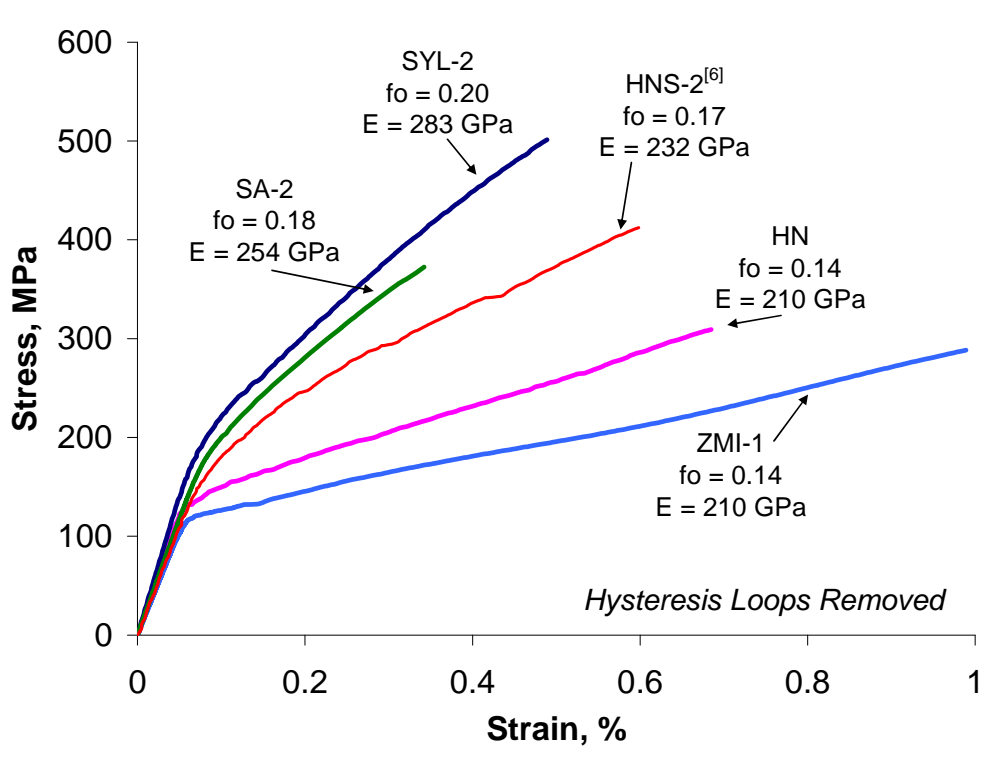

(a)

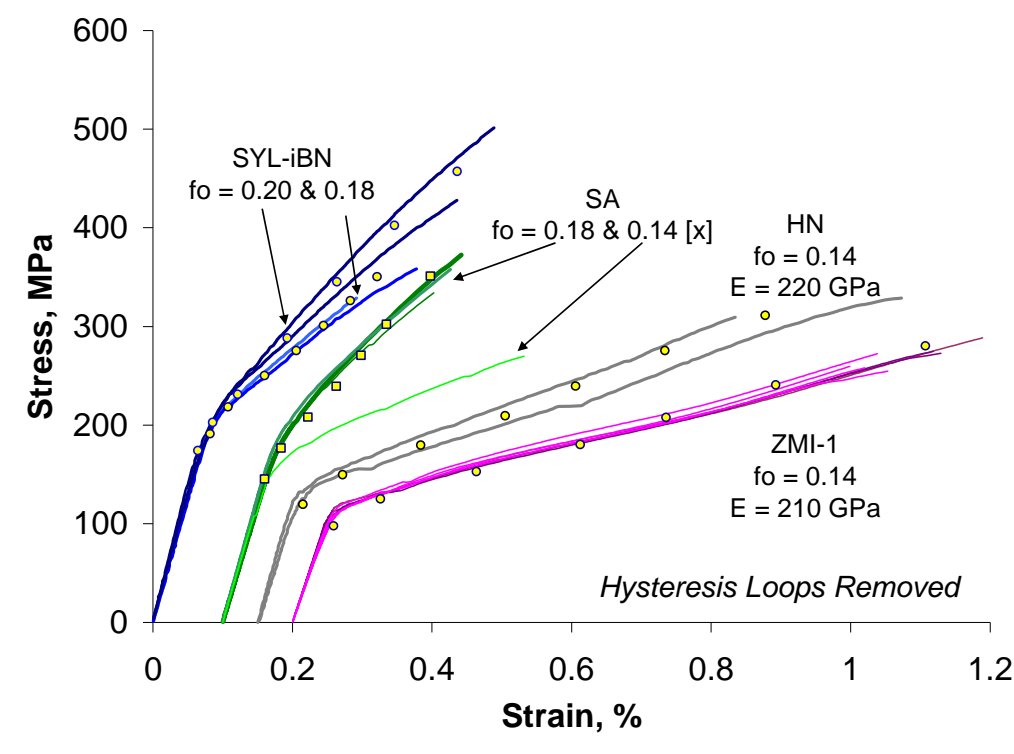

(b)

Figure 1: Representative stress-strain curves from different woven composite systems. 


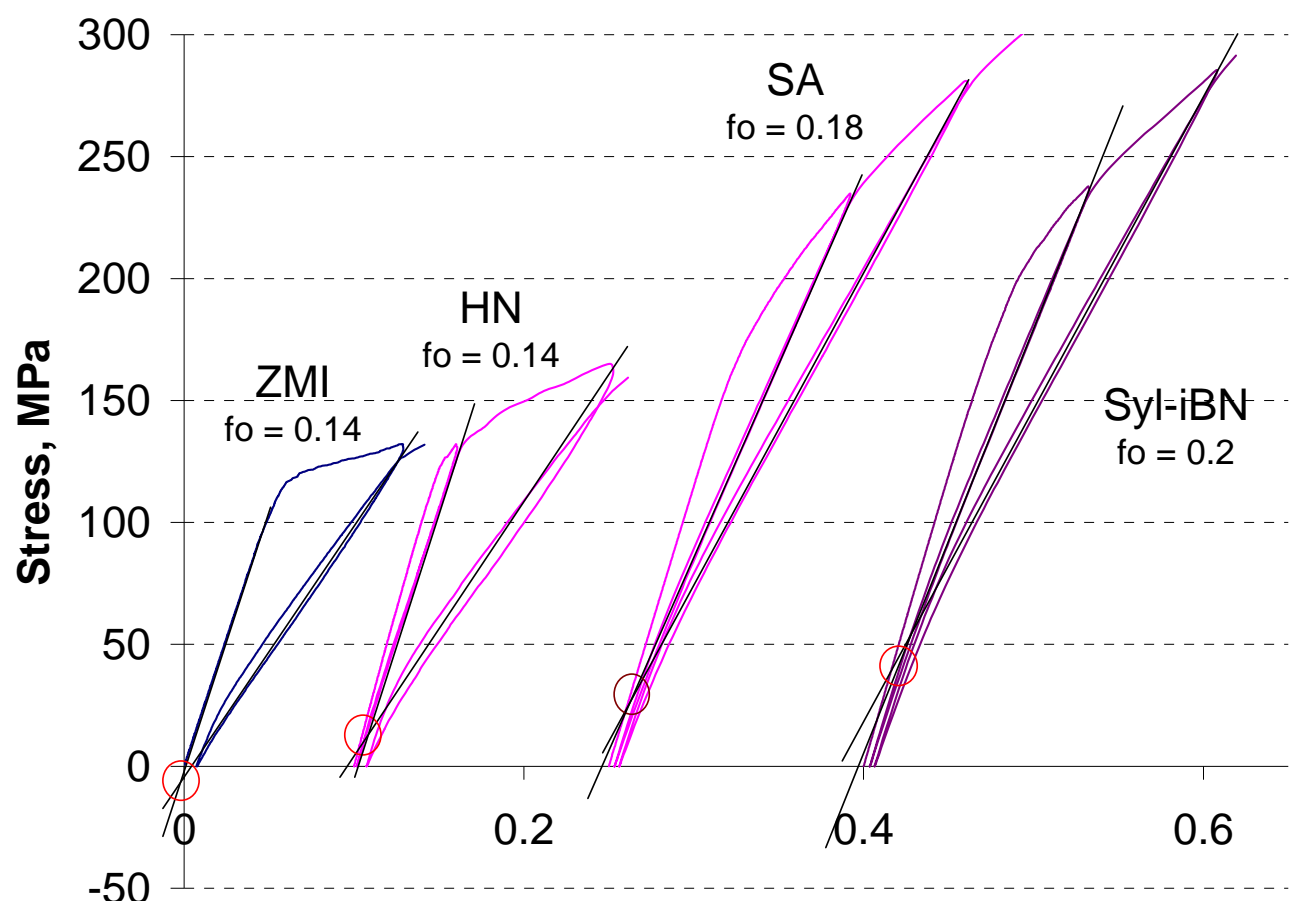

Strain, \%

Figure 2: Initial part of unload-reload stress-strain curves showing residual stress (circles) for representative specimens from each composite system. 


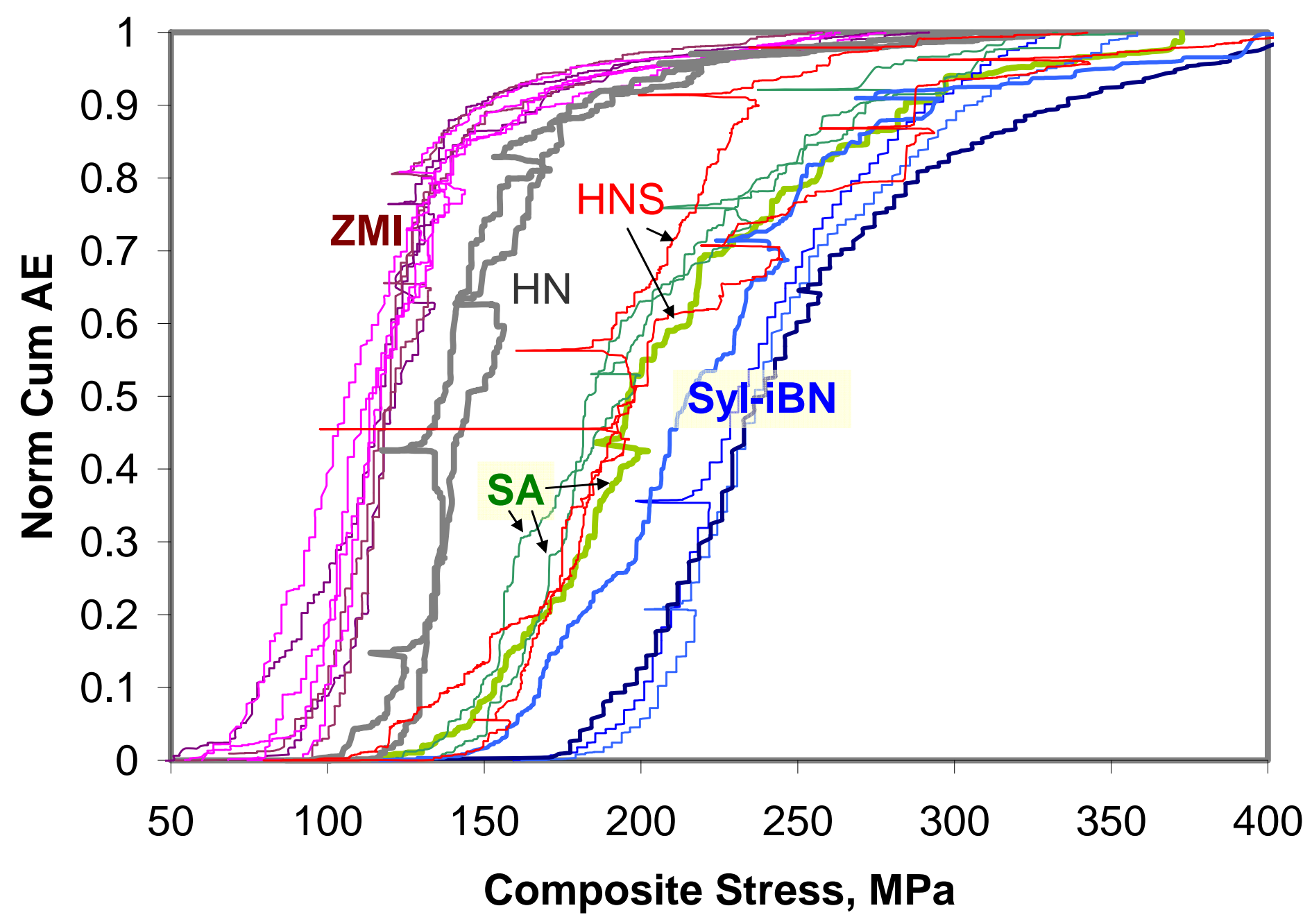

Figure 3: Acoustic emission behavior during room temperature tensile tests on different fiber-containing MI composites. 


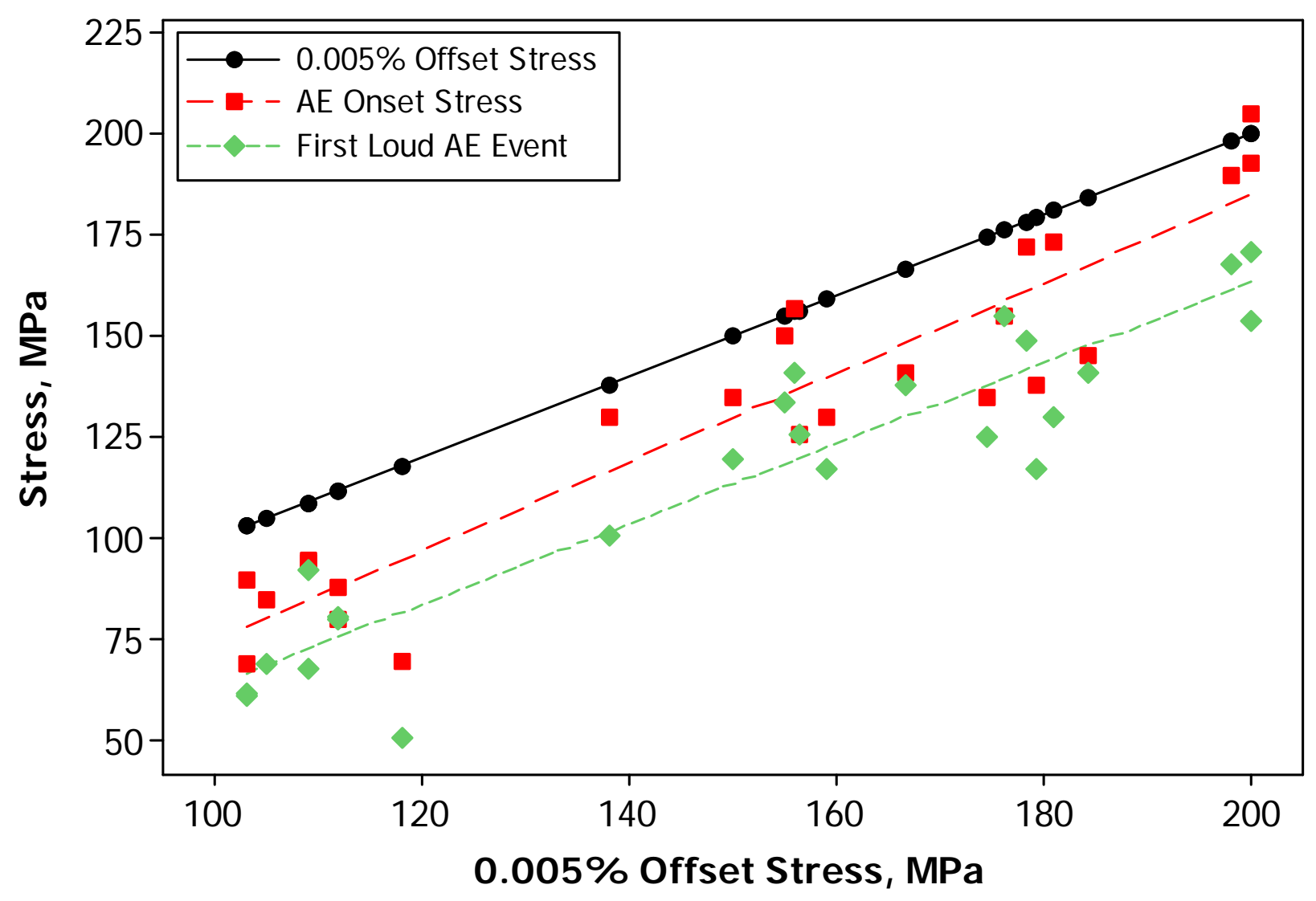

Figure 4: Comparison of $0.005 \%$ offset stress, AE onset stress and $1^{\text {st }}$ Loud AE event for composite specimens tested in this study. 


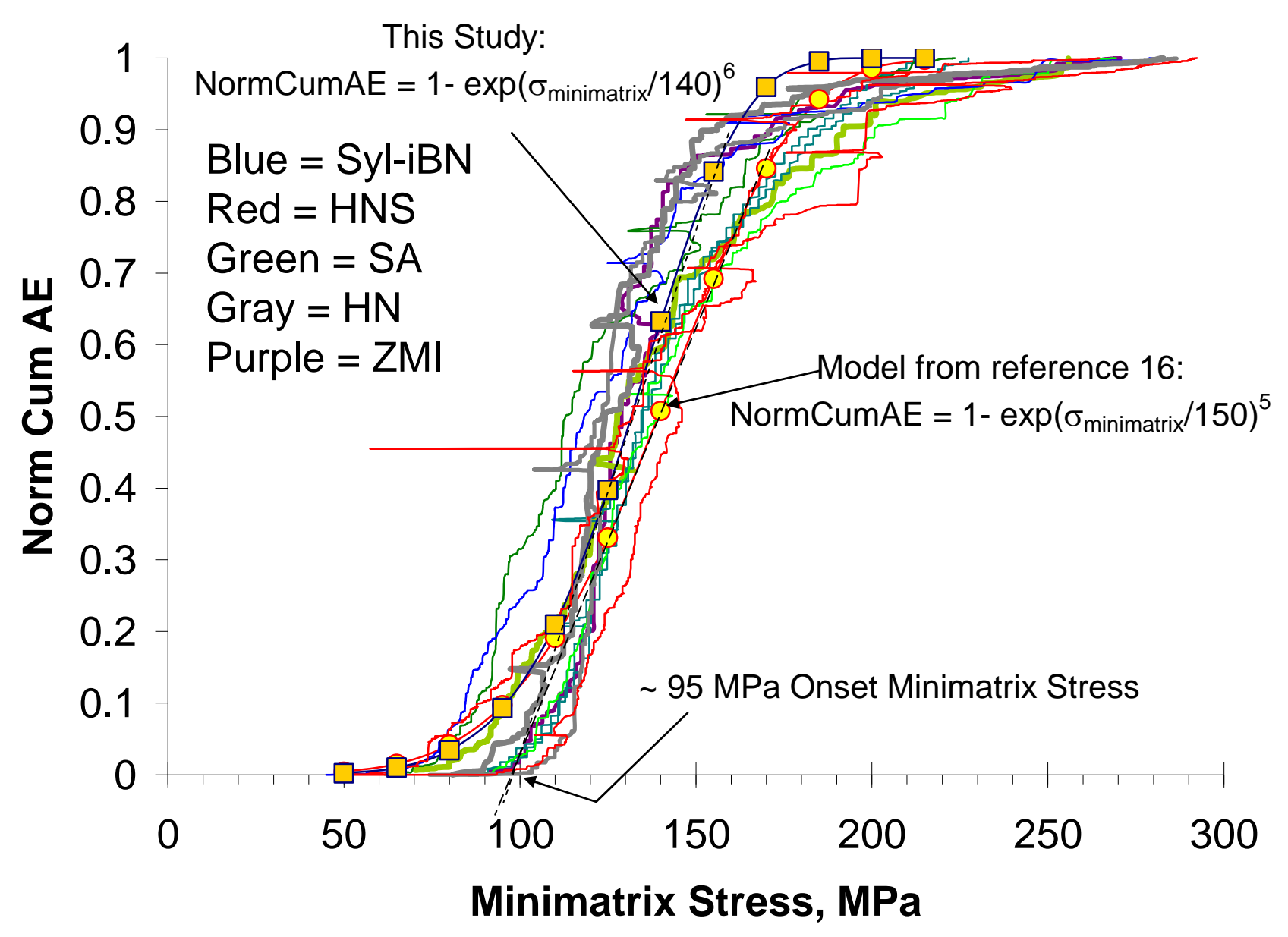

Figure 5: Normalized cumulative acoustic emission energy plotted versus the stress in the matrix outside of the load-bearing minicomposites, i.e., minimatrix stress. 


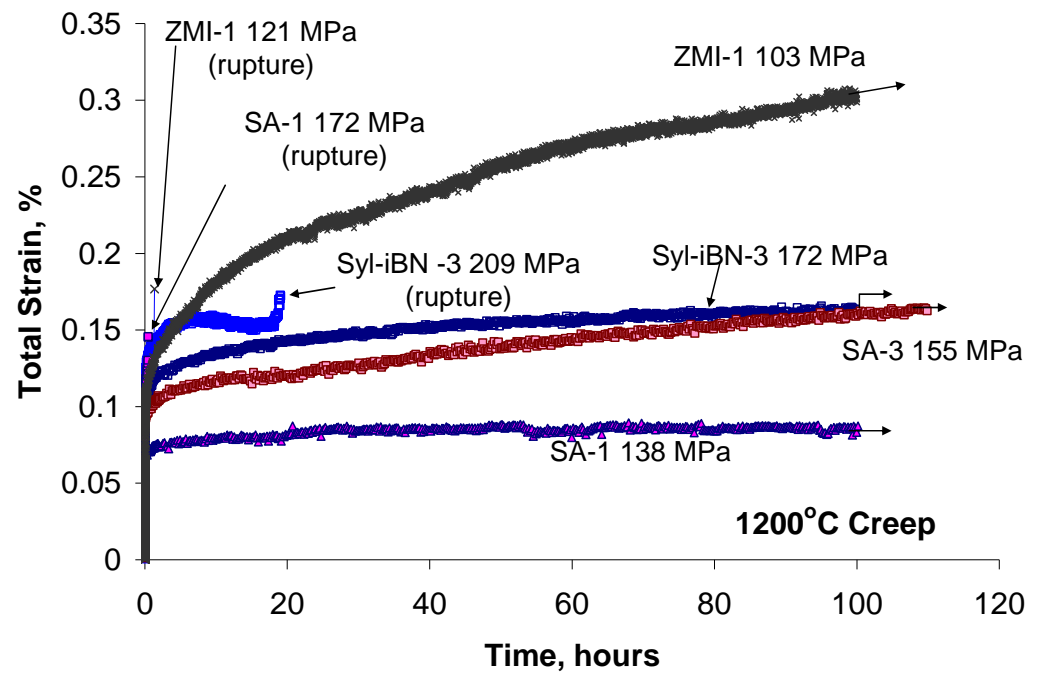

(a)

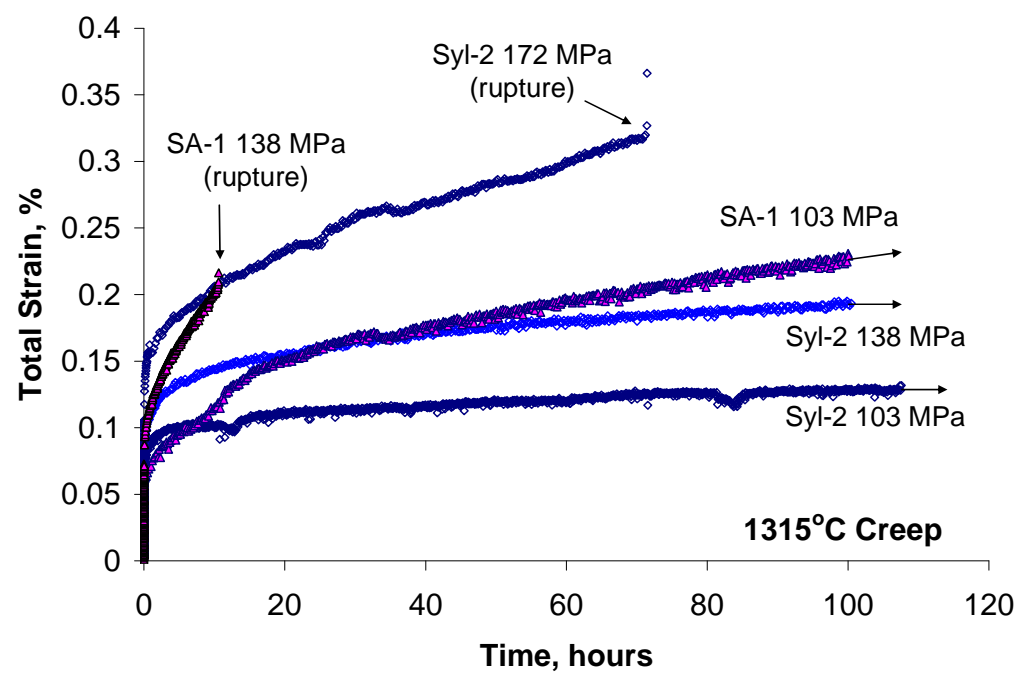

(b)

Figure 6: Tensile creep total strain (elastic plus time-dependent) curves at (a) $1200^{\circ} \mathrm{C}$ and (b) $1315^{\circ} \mathrm{C}$ for different fiber-type MI composites. 


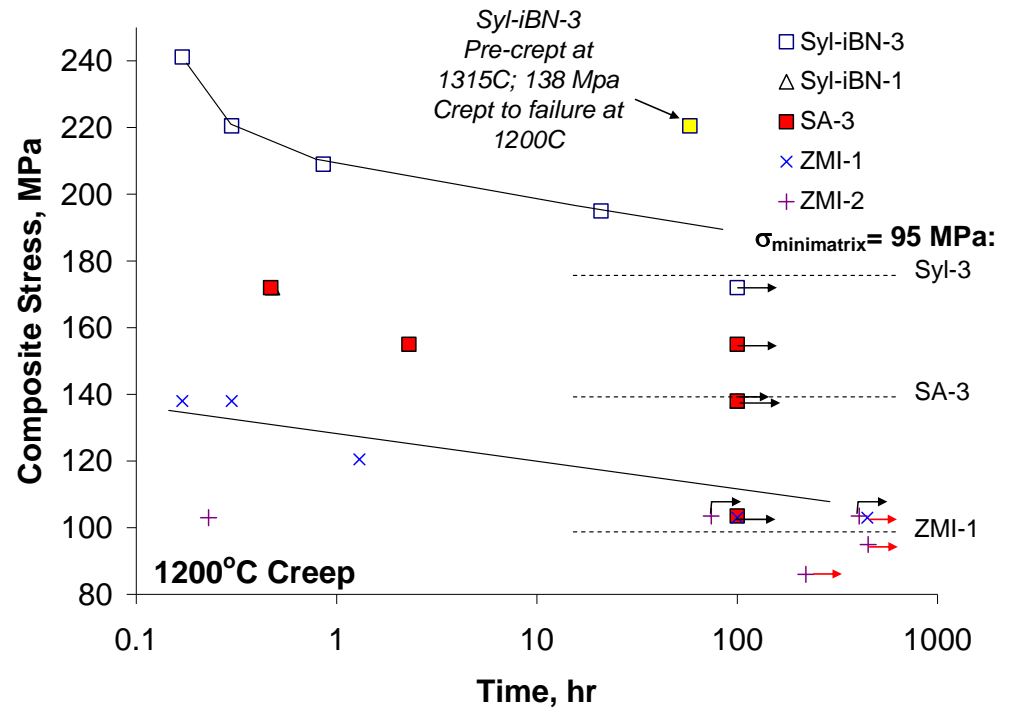

(a)

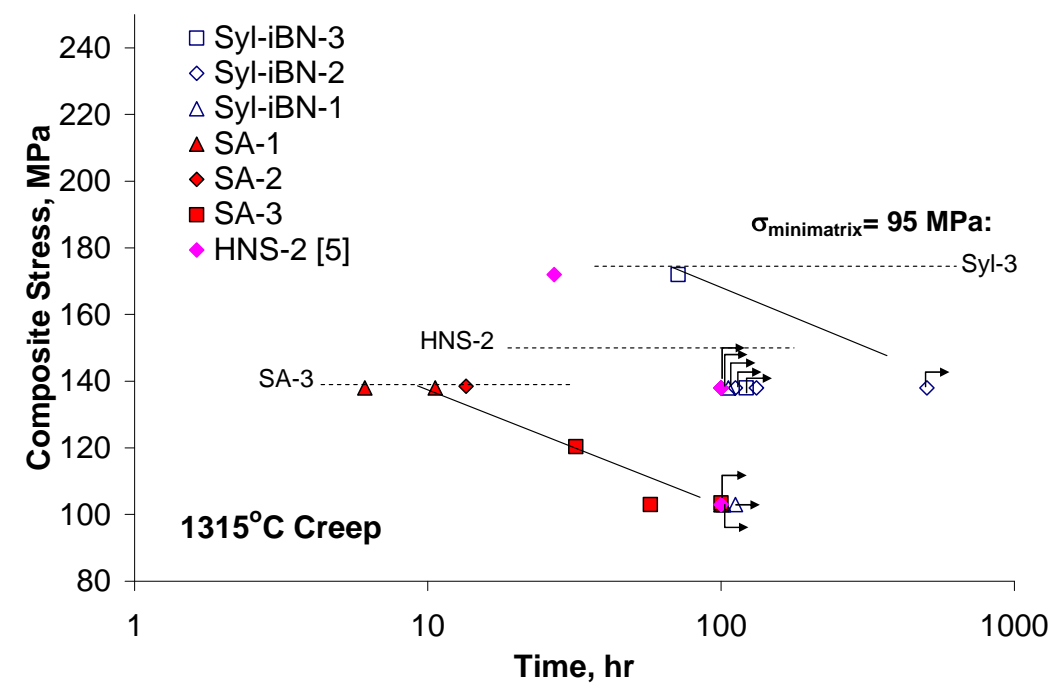

(b)

Figure 7: Tensile creep behavior of different MI composites at (a) $1200^{\circ} \mathrm{C}$ and (b) $1315^{\circ} \mathrm{C}$. Each data point represents an individual specimen. Dashed lines represent the $\sigma_{\text {minimatrix }}=95 \mathrm{MPa}$ stress for designated composite panel. 


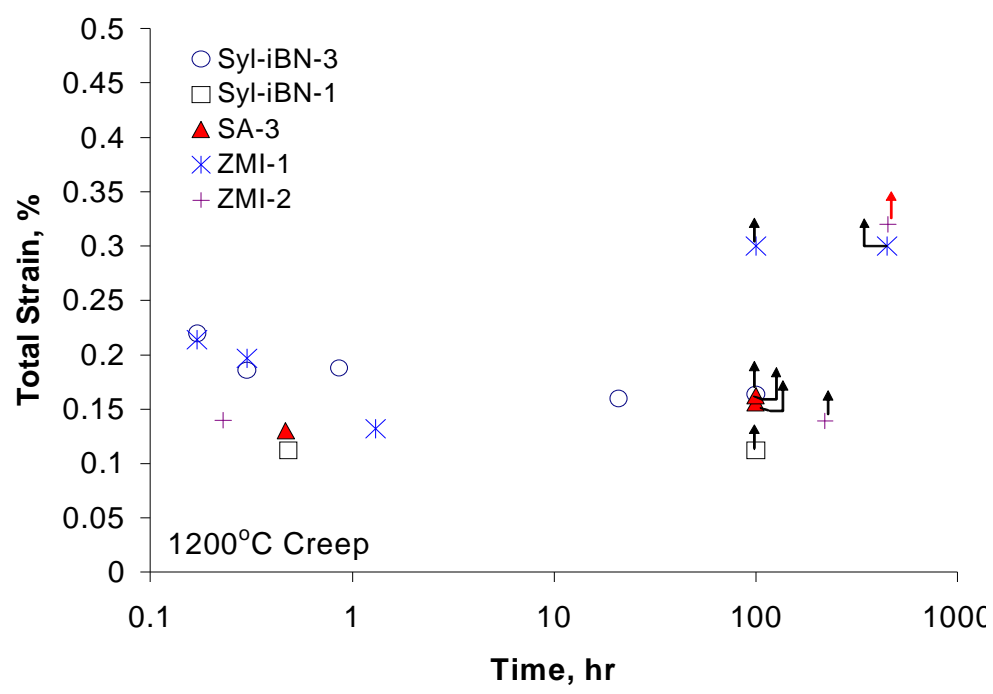

(a)

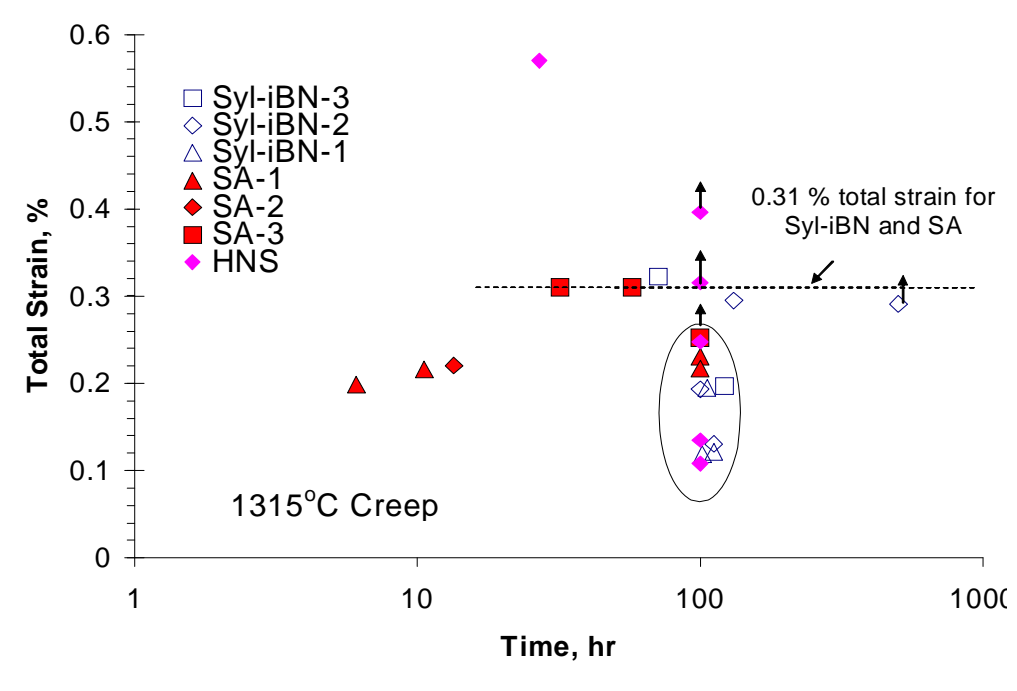

(b)

Figure 8: Tensile creep behavior, total strain vs time, of different $\mathrm{MI}$ composites at (a) $1200^{\circ} \mathrm{C}$ and (b) $1315^{\circ} \mathrm{C}$. Each data point represents an individual specimen. 


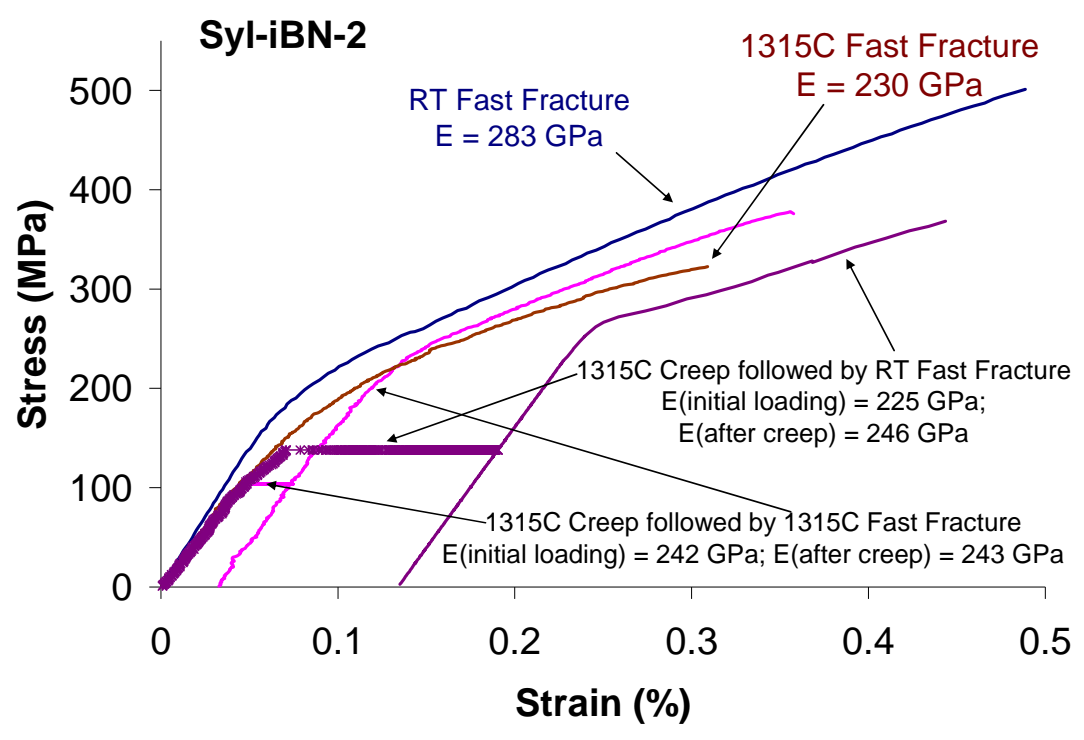

Figure 9: Residual properties after creep for Syl-iBN-2 composites. Some tests were performed at the creep temperature immediately after the creep test (unload, then reload to failure). Other tests were performed at room temperature with several unload-reload hysteresis loops (not shown). Also included are room temperature unload-reload stress strain and elevated stress-strain curves as well as the creep curves in the strain-domain. Note that the hysteresis loops have been removed. 


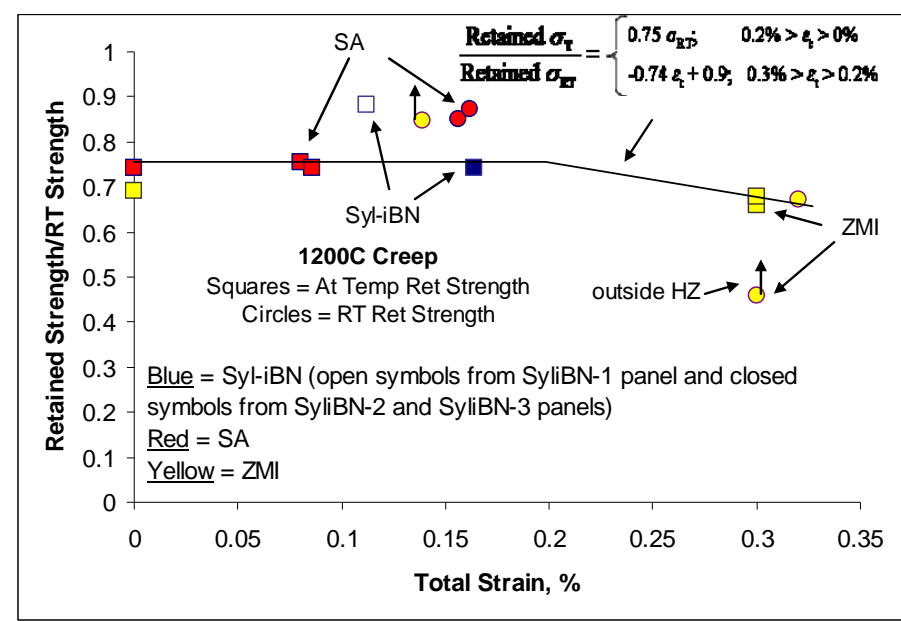

(a)

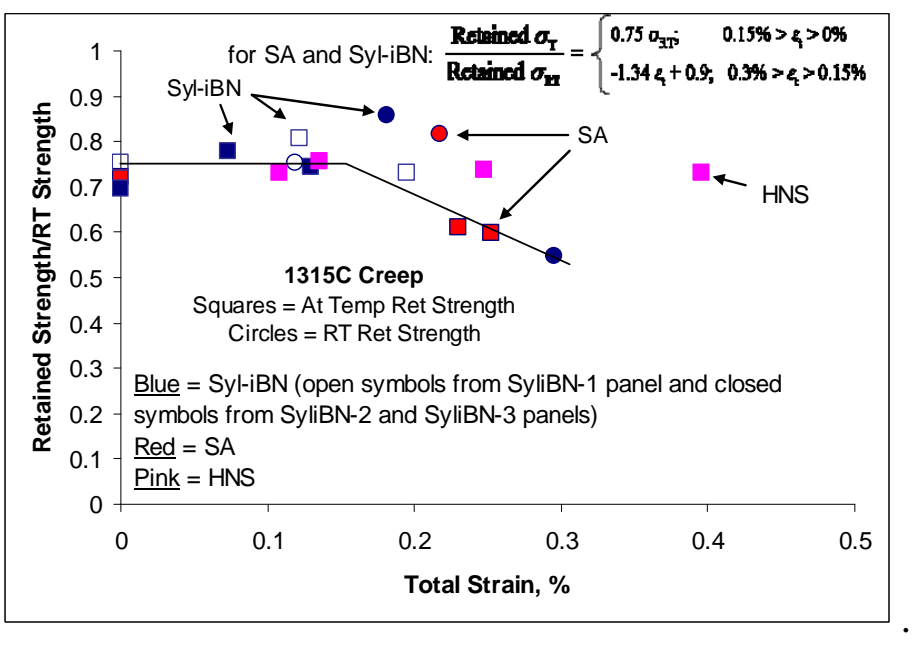

(b)

Figure 10: Retained strength after creep at creep temperature or at room temperature plotted versus total strain normalized by room temperature as-produced ultimate strength for (a) $1200^{\circ} \mathrm{C}$ and (b) $1315^{\circ} \mathrm{C}$ after-creep conditions. 


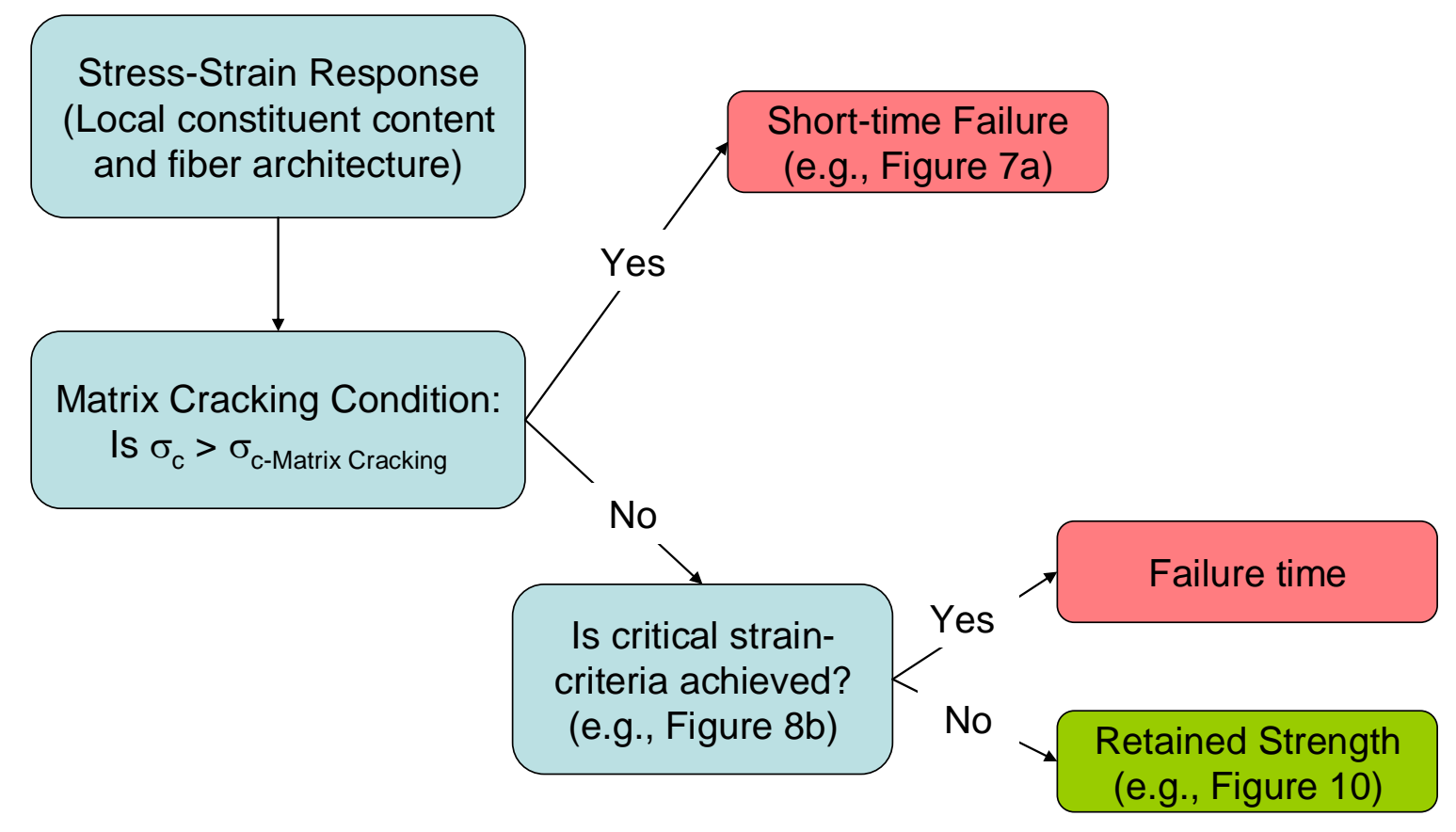

Figure 11: Schematic representation of simple life-modeling procedure. 